\title{
Improving literacy and metacognition with electronic portfolios: Teaching and learning with ePEARL
}

\author{
Elizabeth Meyer ${ }^{\mathrm{a},}$, Philip C. Abrami ${ }^{\mathrm{a}}$, C. Anne Wade ${ }^{\mathrm{a}}$, Ofra Aslan ${ }^{\mathrm{a}}$, Louise Deault a,b
}

\section{Introduction}

Can an electronic portfolio that is both a multimedia container for student work and a tool to support key learning processes have a positive impact on the literacy practices and self-regulated learning skills of students? This article presents the findings of a yearlong study conducted in three Canadian provinces during the 2007-2008 school year initially involving 32 teachers and 388 students. Due to varying levels of implementation our final data set included 14 teachers and 296 students. Using a nonequivalent pretest/post-test design, we found that grade 4-6 students who were in classrooms where the teacher provided regular and appropriate use of the electronic portfolio tool ePEARL (i.e., medium-high implementation condition, $\mathrm{n}=7$ classrooms and 121 students), compared to control students (n = 7 classrooms and 175 students) who did not use ePEARL, showed significant improvements $(\mathrm{p}<.05)$ in their writing skills on a standardized literacy measure (i.e., the constructed response subtest of the Canadian Achievement Test-4th ed.) and certain metacognitive skills measured via student self-report. The results of this study indicate that teaching with ePEARL has positive impacts on students' literacy and self-regulated learning skills when the tool is used regularly and integrated into classroom instruction.

The potential for technology to radically transform and improve education is widely recognized by policy makers, scholars and practitioners (Campuzano, Dynarski, Agodini, Rall, \& Pendleton, 2009; Canadian Council on Learning, 2008; CEO Forum on CEO Forum on Education, 2001; Dynarski et al., 2007; Ungerleider \& Burns, 2003; Zimmerman \& Tsikalas, 2005), however there have been mixed results when new technologies meet the realities of the diverse and changing classroom contexts of North American public schools (Abrami, Savage, Wade, Hipps, \& Lopez, 2007; Abrami et al., 2006; Avramidou \& Zembal-Saul, 2003; Azevedo, 2005; Barrett, 2007; Bernard, Bethel, Abrami, \& Wade, 2007; Cuban, 1993; Cuban, Kirkpatrick, \& Peck, 2001). Electronic portfolios (EPs) are one such innovation that has slowly been introduced in post-secondary environments, and more recently in K12 classroom settings. EPs build on the evidence of what is already known about effective portfolio pedagogy, and makes working with portfolios more engaging, dynamic, and accessible for students, teachers, and parents. EPs can offer valuable opportunities for integrating technology into K-12 classrooms. Not only because they are multimedia containers, but in ways that deepen students' learning experiences by placing the student at the centre of his/her learning and scaffolding essential metacognitive skills such as goal setting, identifying strategies, and reflecting on one's learning. The electronic portfolio tool described in this research project, ePEARL was designed based on Zimmerman's (2000) model of self-regulation. The software was developed using research evidence and feedback from teachers and students in order to build an electronic portfolio that supports the development of selfregulated learning and literacy skills in constructivist classrooms.

\section{Research on electronic portfolios}

An electronic portfolio (EP) is a digital container capable of storing visual and auditory content including text, images, video and sound. EPs may also be learning tools not only because they organize content but also because they are designed to support a variety of pedagogical processes and assessment purposes. Historically speaking, EPs are the Information Age's version of the artist's portfolio for students in the sense that they not only summarize a student's creative achievements but also illustrate the process of reaching those achievements. An artist, architect, engineer, or student who displays her portfolio of work allows the viewer to form a direct impression of that work without having to rely on the judgments of others. EPs tell a story both literally and figuratively by keeping a temporal and structural record of events. Recently, advances in web technologies have provided new opportunities for learning, including life-long learning, resulting in the recommendation that EPs be used as “personal learning environments" (Attwell, 2007; Barrett, 2009) or to represent one’s digital identity of the 21st century (Ravet, 2008).

EPs have three broad purposes: process, showcase, and assessment. EPs may be designed as process portfolios supporting how users learn through embedded structures and strategies. A process EP can be defined as a purposeful collection of student work that tells the story of a student's effort, progress and/or achievement in one or more areas (Arter \& Spandel,1992; Barrett, 2007; MacIsaac \& Jackson,1994). Process portfolios are personal learning management tools. They are meant to encourage individual improvement, personal growth and development, and a commitment to life-long learning. The authors are especially interested in the use of EPs as process portfolios to support learning.

Process EPs are gaining in popularity for multiple reasons (Abrami \& Barrett, 2005; Barrett, 2009; Zubizarreta, 2004). They provide multimedia display and assessment possibilities for school and work contexts allowing the use of a variety of tools to demonstrate and develop understanding especially advantageous for at-risk children whose competencies may be better reflected through these authentic tasks (Barrett, 2007). At the same time, by engaging these learners, their deficiencies in core competencies may be overcome. Process EPs may scaffold attempts at knowledge construction by supporting reflection, refinement, conferencing and other processes of self-regulation, important skills for life-long learning and learning how to learn. They are useful for cataloguing and organizing learning materials, readily illustrating the process of learner development. They can also provide remote access encouraging anywhere, anytime learning and easier input from peers, parents and teachers (Barrett, 2008).

According to Wade, Abrami, and Sclater (2005), process EPs are linked to students' abilities to self-regulate their learning and to enhance their development of important educational skills and abilities, especially literacy skills. Self-regulated learners are individuals who are metacognitively, motivationally, and behaviorally active participants in their own learning (Zimmerman, 1989,2000). A main feature of self-regulated learning is metacognition. Metacognition refers to the awareness, knowledge and control of cognition. The three processes that make up metacognitive selfregulation are planning, monitoring, and regulating. Other aspects of self-regulated learning include time-management, regulating one's own physical and social environment, and the ability to control one's effort and attention. Proponents of socio-cognitive models emphasize that to develop effective self-regulated learning strategies, "students need to be involved in complex meaningful tasks, choosing the products and processes that will be evaluated, modifying tasks and assessment criteria to attain an optimal challenge, obtaining support from peers, and evaluating their own work” (Perry, 1998, p. 716).

When students use portfolios, they assume more responsibility for their learning, better understand their strengths and limitations, and learn to set goals (Hillyer \& Ley, 1996). One study with pre-service teachers noted that using electronic portfolios helped them "engage in metacognitive activities while developing their philosophies", that is they were asked to "critically examine their own beliefs and ideas about teaching and learning" (Avramidou \& Zembal-Saul, 2003, p. 437). Azevedo (2005) conducted case studies with pre-service elementary teachers using hypermedia as a metacognitive tool for enhancing student learning. In his study using web-based portfolios he reported that, "our findings provide the empirical basis for the design of technology-based learning environments as metacognitive tools to foster students' learning of conceptually challenging science topics” (p. 206). Zellers and Mudrey (2007) also suggest that their study on electronic portfolios in a community college setting indicates, “electronic portfolios can be an effective tool for increasing student metacognition” (p. 428). Most recently, Wang (2009) studied the collaborative vs. individual 
use of EPs in a pre-service technology integration course. He reported that students who collaborated showed "more significant improvement in their confidence to perform technology-related tasks than students in the individual portfolio group” (p. 62). As these studies show, most research using EPs has been at the university level with an emphasis in pre-service teacher education.

As Helen Barrett, one of the leading scholars in the area of electronic portfolios points out, "the empirical research is very limited and focuses more on the development of teaching portfolios than on K-12 student portfolios” (p. 486). In 2006, Kate Wall and her colleagues at the University of Newcastle reported on an action research study with primary school pupils in the UK. The goal of this research was to help teachers produce, store, and access assessment portfolios in order to develop more practical approaches to formative assessment practices. The researchers explored pupil talk about their learning processes and they reported that "multimedia can be used to facilitate children's talk about their learning," and that "the reflective nature of the pupil's comments regarding their learning and achievement as part of the digital portfolio gives valuable evidence to support formative assessment theory” (Wall, Higgins, Miller, \& Packard, 2006, p. 271). In a study on collaborative knowledge building with 9th grade students in Hong Kong, Lee, Chan, and van Aalst (2006) reported on the usefulness of a digital portfolio to track and promote student discussion and understanding using a program called Knowledge Forum. In a quasi-experimental design with four classrooms and four treatments (Knowledge Forum only, Knowledge Forum with portfolios, Knowledge Forum with portfolios guided by knowledge building principles, and paper portfolio only), they used a portfolio to track, "group accomplishment with multiple contributions from the community" (p. 305) in order to trace the path of knowledge formation. In their study, they found that students who used the electronic portfolio "participated more and engaged in deeper inquiry" (2006, p. 301). Helen Barrett’s (2007, 2008) project on using Task-Stream in US high schools resulted in limited data on the actual use of EPs so she reported more extensively on issues of implementation and teacher support. She did note that, "teachers who understood reflection and metacognition and used assessmentfor learning strategies to provide quality feedback to their students were most often in the High [implementation] group” (p. 447). Finally, Kim and Olaciregui (2008) reported on a project that examined the use of a concept map-based information visualization to inform the design of a web-integrated electronic portfolio system in a 5th grade science class. This study was a design-based project with an emphasis on learning content rather than documenting student learning processes. The researchers reported that a concept map design improved student comprehension, access time, and retention compared to students who accessed a portfolio organized in a traditional "tree" format (p. 709). In short, educators believe that portfolios allow students to think critically, and become active, independent and self-regulated learners (Blackburn \& Hakel, 2006; Lambert, DePaepe, Lambert, \& Anderson, 2007; Mills-Courts \& Amiran,1991; Perry, 1998; Riedinger, 2006). Zimmerman and Tsikalas’ (2005) review of computer-based learning environments (CBLEs) designed to support self-regulated learning (SRL) provides a framework for the development of a tool to support the three cyclical phases of SRL: forethought, performance and self-reflection. The lessons learned from other partially SRL-supportive CBLEs has enabled us to plan for effective SRLsupportive design of ePEARL.

Recently, Zimmerman published an overview of SRL research that studied several online tools designed to stimulate and study various SRL processes in students (Zimmerman, 2008). He identified four key trends that remain as important questions in this field of research including: the relationship between student reports of SRL and actual use of SRL processes, the relationship between levels of SRL and overall academic achievement, the role of the social context of the classroom in stimulating or hindering the development of SRL skills, and finally the relationship between motivation and SRL processes. The research presented in this article addresses two of these four areas: the relationship between levels of SRL and overall academic achievement, and the role of the social context of the classroom in stimulating or hindering the development of SRL skills.

Unfortunately, evidence to date on the impacts of EPs on learning and achievement and other outcomes is sparse. Carney (2005) states "Electronic portfolios show promise for enhancing learning, but if we fail to critically evaluate our uses of the device, we may find that they will go the way of Papert's Logo turtles and become yet another educational fad - an innovation poorly understood and often implemented in ways contrary to its theoretical underpinnings" (p. 4). Zeichner and Wray (2001) concluded similarly: "Despite the current popularity of teaching portfolios, there have been very few systematic studies of the nature and consequences of their use for either assessment or development purposes” (p. 615). Our research is designed to fill this gap by studying the impact of EPs on teaching and learning processes, especially those related to self-regulation, in late elementary classrooms. Results from our first year of research (2006-2007) indicate that there are many challenges facing K-12 teachers who attempt to integrate electronic portfolios into their teaching. Although the teachers in our study had a positive view of electronic portfolios and self-regulated learning processes, we learned that many teachers needed to adjust their teaching styles and strategies to effectively incorporate ePEARL into their teaching and that levels of use throughout the school year were fairly low (Abrami, in press; Abrami, Wade, Aslan, Bures, \& Bentley, 2008).

\section{About ePEARL}

The Research Centre in city, in collaboration with our partner. The Leading English Education and Resource Network, LEARN (www. learnquebec.ca), developed ePEARL as a bilingual (English-French), web-based, student-centred electronic portfolio software, that is designed to support the phases of self-regulation. The three cyclical phases of self-regulation include both metacognitive and motivational components, providing the foundation for better sustainability of learning and skill development. The forethought phase includes task analysis (goal setting and strategic planning) and self-motivation beliefs (self-efficacy, outcome expectations, intrinsic interest/value and goal orientation). Tasks involved in the forethought phase are: set outcome goals, set process goals, document goal values, plan strategies, and set up learning logs. The next phase, the performance phase, includes self-control (self-instruction, imagery, attention focusing and task strategies) and self-observation (self-recording and self-experimentation). Tasks involved in the performance phase are: creation of work, and learning log entries. Finally, the self-reflection phase includes self-judgment (self-evaluation and casual attribution) and self-reaction (self-satisfaction/affect and adaptive-defensive responses) (Zimmerman, 2000). Tasks involved in the self-reflection phase are: reflection on work, reflection on process, and awareness of new goal opportunities.

Developed in PHP using a MySQL database, three levels of ePEARL have been designed for use in early elementary, late elementary, and secondary schools. Features available include: personalizing the portfolio; setting outcome and process goals; creating new work; linking to existing work; reflecting on work; sharing work; obtaining feedback from teachers, peers \& parents; editing work; saving work under multiple versions and sending work to a presentation folder. ePEARL is available at no cost to schools. ePEARL promotes: the creation of general learning goals fora term or year, or for a specific work/artifact; reflection; and peer, parent and teacher feedback on the portfolio or on a specific artifact. ePEARLguides students through the creation process, allowing enough flexibility for truly creative work and just enough scaffolding to keep students on the right track. It offers a text editor and an audio recorder for the creation of work. Readings, music pieces, or oral presentations may be recorded. The software also offers the ability to attach work completed using other software, so it can accommodate any kind of digital work a student creates, including videos, slideshows, podcasts, scanned images or photographs of paperbased work.

Before work is created, students are encouraged to set their goals for this work, and may attach learning logs, evaluation rubrics and study plans to keep track of their learning process as it takes place. After the creation of work, sharing with peers or teachers is supported so that students may solicit feedback on drafts of work. Students may also reflect on their performance and strategies, and to use these to adjust their goals for the next work.

The presentations folder is where students collect their selected artifacts - created either from within ePEARL's text editor or audio recorder, or from outside of the tool. The selection process allows students to reflect on why they feel a work belongs in their portfolio, its relationship to other work, and on their own advancements. Self-regulation is also supported when students create new goals for future work or modify learning behavior based on their 
reflections on a particular piece they have collected. Sharing with peers and parents is encouraged and teachers have automatic access to view all of their students' ePEARLs.

In addition, there are both prose and multimedia support materials for teachers and students to develop a better understanding of the what, why and how of the process of self-regulation using the learning process supported by ePEARL. Embedded within ePEARL, the professional development just-intime materials support the demonstration and modeling of student-centred skills and instruction, explanation of those skills, and elaboration of skills through additional support material. In fact, we went to some length to insure that both students and teachers were knowledgeable in the features of ePEARL and the processes of SRL. This occurred not only through the embedded multimedia but also because of the training and follow-up support we provided throughout the project. ePEARL is available without charge to educators. The latest version may be explored by going to http://grover.concordia.ca/epearl/en/index.php. The version (2.0) used in this research is archived on our university server.

\section{Research context and method 4.1. Study Design}

Participants in this study were 32 teachers from elementary schools (grades 4-6), and their students (n = 388) from nine urban and rural English school boards in Quebec, Manitoba, and Alberta who participated during the 2007-2008 school year. All experimental teachers ( $\mathrm{n}=16)$ received at least a half-day of training on the use of ePEARL from research centre staff and follow-up support including lesson plans and job aids, an online discussion forum (in the form of a moderated wiki), as well as in-class observations and model lessons during the school year. In addition, multimedia scaffolding and support for teachers and students are embedded in the tool. At the conclusion of the school year, experimental teachers were offered additional training to deepen their understanding of ePEARL, portfolio pedagogy, and to introduce them to the new version of ePEARL (3.0) that was launched in August 2008.

We worked actively with school principals and school board administrators to identify control teachers and their classrooms who would match as closely as possible the experimental teachers and their classrooms. All teachers needed to follow provincial curriculum requirements for the development of language arts. Experimental teachers did so with the aid of ePxxx, while control teachers did not. All teachers were at liberty to decide on the provision of language arts instruction. There were no special language arts materials provided to either experimental or control teachers by the research team. Given there was little incentive to participate as a control group; teachers were offered a stipend that could be used towards the purchase of classroom resources or professional development. We were unable to randomly assign teachers and their students to conditions and relied on statistical means to deal with group inequivalence. Informed consent was obtained from students' parents following Canada's Tri-Council Policy on the ethical treatment of research participants.

The design of the study was a two-group repeated measures design. Teacher and student questionnaire data were collected in the fall of 2007 prior to the use of ePEARL in classrooms. Teacher and student questionnaire data were collected again in May and June of 2008 after ePEARL was used for some part of the school year ranging from 6 to 8 months. In addition to questionnaires, all students completed the constructed response of the Canadian Achievement Test (version 4) in both the fall and the spring to assess their reading and writing skills. A sample of student portfolios ( $\mathrm{N}=133$ ) were also analyzed using a rubric to assess the use of SRL and literacy skills (Bures, Barclay, Abrami, \& Meyer, 2009).

\subsection{Instrumentation}

Abrami, Aslan, and Nicolaidou (2007) developed the Teaching and Learning Strategies Questionnaire (TLSQ) as a way for teachers to describe their use of self-regulation strategies and portfolio processes in their classrooms. Abrami and Aslan (2007) developed the Student Learning Strategies Questionnaire (SLSQ) in parallel with the TLSQ. These instruments were developed based on Zimmerman's (2000) research and an analysis of recent literature on self-regulated learning processes. The TLSQ contains several open-ended and 73 close-ended Likert scale questions, the latter divided into four sections: students' learning strategies ("In my class students generally set their own learning goals”), approach to teaching ("In my class I teach students how to identify strategies for achieving their goals"), portfolio use ("In my class portfolios are used for students to document their progress"), and technology experience ("With regard to computer technologies for education: I feel comfortable using them in my classroom."). This instrument was piloted in the field during the pilot study (2006- 2007) and several open-ended questions were added for use in this study. In our analysis we looked at the 47 items that were common to the experiences of both the experimental and control teachers, excluding items dealing with portfolio practices, for example, since they had little or no meaning for teachers in the control condition.

Abrami and Aslan (2007) also developed the SLSQ as a way to triangulate the data from the TLSQ and further validate the occurrence of selfregulation processes and portfolio use in classroom. The SLSQ contains several open-ended questions and 20 close-ended Likert scale questions designed to match the learning strategies questions asked of teachers. The SLSQ measures students' perception of their ability to employ SRL strategies including their ability to set learning goals, observe and correct their performance and reflect on the learning outcome. Reliability and validity information are reported in the results.

The constructed response subtest of the most recent version of the Canadian Achievement Tests (CAT-4) was also administered to students in both the fall and the spring (Canadian Achievement Tests, fourth edition, 2008). The CAT-4 assesses both response to text (ideas, support) and writing (content, content management) using a rubric. The Canadian Test Centre conducted all scoring as part of their norming study. The constructed response subtest depends on student narrative responses to prompts as opposed to the multiple-choice format of the main tests of the CAT-4, which also measures student literacy. Multiple story prompts were used in each class at both pre-test and post-test but no student responded to the same prompt twice. We chose this form of measuring literacy achievement because it was compatible with notions of authentic assessment, even though it meant we generated a less detailed analysis of student learning than using the closed ended version of the CAT-4. The reliability coefficients (KR-20) for CAT-4 subtests range between 0.85 and 0.95 , depending on the level and subtest. In the previous version (CAT-3), test validity was established by showing that grade levels who were known to have different levels of achievement did indeed have different mean scores on the same test.

At two points during the year, teachers completed an Implementation Fidelity Questionnaire (IFQ) that asked them to report on how many hours a month they had been using ePEARL as well as describe what was going well and what were challenges they were facing. In order to measure implementation fidelity, we developed the Implementation Assessment Protocol (IAP). This protocol assessed the data reported on the IFQ and a sample of student portfolios in each classroom to determine the following: average number of artifacts, date range of use, and the degree to which students were using all of the available features of ePEARL such as: goal setting, feedback, and reflection. Each experimental classroom was assigned a degree of implementation: low, medium, or high, based on the IAP. Low implementation classrooms were identified as those that reported less than 4 h of ePEARL use each month and the student portfolios analyzed had 0-3 student entries and the entries were often incomplete. Medium-high implementation classrooms reported using ePEARL 5 or more hours each month and each student portfolio had at least four artifacts that included goals, content and a reflection. Table 1 provides an overview of the IAP's criteria.

At the end of the school year, teacher exit interviews were conducted in experimental classes using the Teacher Exit Interview Protocol (TEIP). This semi-structured interview protocol was designed to explore the reasons for teachers' varying degrees and types of implementation including: their expectations, access to technology, support from administration and tech personnel, familiarity with portfolio pedagogy, knowledge of SRL processes, and 
time management issues. At the same time, teachers in experimental classrooms also completed the Technology Implementation Questionnaire (TIQ; Wozney, Venkatesh, \& Abrami, 2006). The TIQ measures teachers' experiences with and attitudes towards technology using factors that measure expectancy, value and cost. Teachers also completed a section entitled "Process of Integration", which asked them to rate the ways in which they use technology in their classrooms (Instructional, Communicative, Organizational, Analytic/Programming, Recreational, Expansive, Creative, Expressive, Evaluative and Informative).

Table 1

Implementation Assessment Protocol (IAP).

\begin{tabular}{|c|c|c|c|}
\hline Criterion & Low & Medium & High \\
\hline IFQ - h/month & $h \leqslant 4$ & $5-12$ & $13 \leqslant h$ \\
\hline Avg. \# artifacts & Artifacts $\leqslant 3$ & $4-6$ & $7 \leqslant$ artifacts \\
\hline $\begin{array}{l}\text { Date range of } \\
\text { use }\end{array}$ & Entries span less than 60 days & Entries span $61-120$ days & Entries span 121 days or more \\
\hline $\begin{array}{l}\text { Student use of } \\
\text { ePEARL }\end{array}$ & $\begin{array}{l}\text { - Storage only } \\
\text { - Incomplete entries } \\
\text { - No, minimal, or incorrect use } \\
\text { of SRL processes }\end{array}$ & $\begin{array}{l}\text { - At least two general goals } \\
\text { - At least three artifacts have goals/strate- } \\
\text { gies, content, and reflection } \\
\text { - Some feedback provided; some may not } \\
\text { be appropriate } \\
\text { - Artifacts may be in only one subject area }\end{array}$ & $\begin{array}{l}\text { - Three or more general goals } \\
\text { - More than three artifacts have goals, strategies and } \\
\text { reflection } \\
\text { - Extensive use of feedback by teacher, students, and par- } \\
\text { ents; most is developmentally appropriate } \\
\text { - Creative use of ePEARL } \\
\text { - Artifacts included from multiple subject areas }\end{array}$ \\
\hline
\end{tabular}

\subsection{Analysis}

We began by identifying the levels of implementation of each of the participating 16 experimental classrooms. We applied the Implementation Assessment Protocol (IAP) to rate each classroom as "low," "medium," or "high" degree of implementation. The IAP was applied at two points during the research cycle: in April prior to post-test and in June at the end of data collection to ensure that the experimental classes included in the data set met our minimum implementation criteria. Classrooms that were categorized as low implementation $(\mathrm{n}=9)$ were dropped from the data set entirely as they did not have sufficient exposure to the tool to expect treatment effects. Their equivalent control schools were also dropped from the analysis $(n=9)$ leaving a total of 14 classrooms in the data set (experimental $=7$, control = 7).

All survey data were entered into SPSS 11.0.4 for Mac OS X (18 Aug 2005) by two graduate research assistants and verified for accuracy. Partially missing data for participants was accounted for using mean substitution. For all measures, analyses were run using a 2 x 2 repeated measures design, with the treatment (ePEARL, control) as the between-subjects variable and time of testing (pre-test-post-test) as the within-subjects variable. All analyses reported reflect the treatment by time interaction, which enables us to examine whether participants made significant improvements over time as a function of group (ePEARL vs. control). Questionnaire data were analyzed by item, to obtain a fine-grained analysis of specific changes in self-regulation that occurred as a result of ePEARL use. The results of the Canadian Achievement Test (4th version) constructed response reading and writing activities were sent to the Canadian Test Centre for evaluation. They assigned final scores to all the students that were then mailed to us for inclusion in our data set.

\section{Findings}

Two raters analyzed a random sample of each classroom's portfolios and independently assigned each classroom a rating of low, medium or high implementation based on the criteria outlined in the IAP. Raters achieved a reliability of .70 across classrooms and together determined the IAP scores for each of the experimental classrooms. Following the application of the IAP, the final sample included seven experimental classrooms, coded as medium or high implementation ( $\mathrm{n}=121$ students) and seven control classrooms ( $\mathrm{n}=175$ students).

The repeated measures analyses of the CAT-4 data also showed that students in ePEARL made significantly greater gains compared to controls in writing skills as assessed on the constructed response subtest of the CAT-4. Students who were in medium-high implementation classrooms also showed significantly larger improvements compared to controls in content management $(F=(1,293)=7.749$, $p<0.01)$, which refers to the word choice, sentence structure and conventions of print. However, students in both groups showed comparable gains in terms of the content of their writing and in reading comprehension responses (see Table 2).

The student questionnaire (SLSQ) data showed that students who used ePEARL reported higher levels of some specific SRL processes including: setting process goals $(F=(1,293)=6.571, p<0.01)$, listing strategies $(F=(1,293)=8.095$, $p<0.01)$ and using comments from their teacher to improve on work $(\mathrm{F}=(1,293)=9.992, \mathrm{p}<0.01)$. There was also a trend towards significance for changes in student understanding of how they are being evaluated $(\mathrm{F}(1,293)=3.988, \mathrm{p}=0.05)$. Cronbach's alpha was calculated to determine the internal consistency of the SLSQ. Respondents who completed less than $75 \%$ of the questions were excluded from the analysis. Missing values were replaced by the mean value of the item. The SLSQ Cronbach's alpha was obtained using the pre-tests results. Cronbach's alpha obtained was .80 (see Table 3).

As with the SLSQ, the Teaching and Learning Strategies Questionnaire (TLSQ) similarly showed that teachers reported changes in the degree to which they felt their students were adopting self-regulation strategies. Compared to control classrooms, teachers who used ePEARL reported improvements in their students' use of the following self-regulation strategies: setting their own process goals $(\mathrm{F}=(1,14)=5.855$, $\mathrm{p}<0.05)$, articulating task demands $(\mathrm{F}=(1,14)=8.854, \mathrm{p}<0.05)$, documenting strategies $(\mathrm{F}=(1,14)=5.283$, $\mathrm{p}<0.05)$, providing constructive feedback to peers $(F=(1,14)=6.769, \mathrm{p}<0.05)$, using both teacher feedback $(\mathrm{F}=(1,14)=6.818, \mathrm{p}<0.05)$ and peer feedback to revise their own work $(\mathrm{F}=$ $(1,14)=7.737, p<0.05)$, and evaluating their own work $(F=(1,14)=7.385, p<0.05)$. In terms of their own approach to teaching, experimental teachers reported changes in the degree to which they explicitly teaching the following skills, relative to the control teachers: monitoring progress towards goals $(\mathrm{F}(1,14)=6.818, \mathrm{p}<0.05)$, modifying strategies $(\mathrm{F}(1,14)=9.000, \mathrm{p}<0.05)$, using peer feedback $(\mathrm{F}(1,14)=7.680$, $\mathrm{p}<0.05)$ and attributing success to effort $(F(1,14)=5.217, \mathrm{p}<0.05)$. The TLSQ Cronbach's alpha was obtained using the method described above for the SLSQ. Cronbach's alpha obtained was .91.

Univariate analyses were run to compare teachers on the technology use items of the TIQ. While teachers did not differ overall in their range of technology use $F(1,14)=0.605$, ns, teachers coded as medium/high reported that they were more likely to use technology for Creative $F(1,14)=6.000$, $\mathrm{p}<0.05$ and Evaluative $\mathrm{F}(1,14)=46.000, \mathrm{p}<0.05$ purposes in their classroom as compared to classrooms coded as low implementers. There was also a trend towards the use of technology for Informative purposes $F(1,14)=4.500, p=0.05$ in medium/high implementation classrooms. 


\begin{tabular}{|c|c|c|c|c|c|c|c|c|}
\hline \multirow[t]{2}{*}{ CAT-4 } & \multicolumn{3}{|c|}{ ePEARL means } & \multicolumn{3}{|c|}{ Control means } & \multirow[t]{2}{*}{$F$ value (implmnt ${ }^{\mathrm{a}}$ prepost) } & \multirow[t]{2}{*}{ Significance, $p$} \\
\hline & Pre & Post & Change & Pre & Post & Change & & \\
\hline Response to text - ideas & 2.06 & 2.04 & -0.02 & 2.10 & 2.15 & +0.05 & 0.437 & ns \\
\hline Standard deviation & 0.725 & 0.614 & & 0.635 & 0.653 & & & \\
\hline Response to text - support & 1.72 & 1.84 & +0.12 & 1.88 & 2.01 & +0.13 & 0.005 & ns \\
\hline Standard deviation & 0.724 & 0.686 & & 0.705 & 0.661 & & & \\
\hline Writing - content & 2.10 & 2.30 & +0.20 & 2.11 & 2.23 & +0.12 & 0.683 & ns \\
\hline Standard deviation & 0.653 & 0.630 & & 0.656 & 0.632 & & & \\
\hline Writing - content management & 1.78 & 2.11 & +0.33 & 1.95 & 2.05 & +0.10 & 7.479 & $<0.01$ \\
\hline Standard deviation & 0.750 & 0.668 & & 0.708 & 0.718 & & & \\
\hline
\end{tabular}

a $n=121$ (experimental), 175 (control).

Table 3

SLSQ between-subjects repeated measures analysis.

\begin{tabular}{|c|c|c|c|c|c|c|c|c|}
\hline \multirow[t]{2}{*}{ SLSQ item } & \multicolumn{3}{|c|}{ Medium/high means } & \multicolumn{3}{|c|}{ Control means } & \multirow[t]{2}{*}{$F$ value (implmnt ${ }^{\mathrm{a}}$ prepost) } & \multirow[t]{2}{*}{ Significance, $p$} \\
\hline & Pre & Post & Change & Pre & Post & Change & & \\
\hline (2) I set my own process goals & 3.45 & 3.71 & +0.26 & 3.63 & 3.50 & -0.13 & 6.571 & $<0.05$ \\
\hline Standard deviation & 0.912 & 0.889 & & 0.935 & 0.964 & & & \\
\hline (4) I revise my goals when necessary & 3.69 & 3.68 & -0.01 & 3.85 & 3.58 & -0.27 & 2.758 & $<0.01$ \\
\hline Standard deviation & 0.911 & 0.896 & & 0.967 & 0.937 & & & \\
\hline (7) I list the strategies I am using when I work on assignments & 3.08 & 3.36 & +0.28 & 3.31 & 3.13 & -0.18 & 8.095 & $<0.01$ \\
\hline Standard deviation & 1.13 & 0.957 & & 1.06 & 1.14 & & & \\
\hline (12) I use comments from my teacher to improve on my work & 3.96 & 4.24 & +0.28 & 4.21 & 4.06 & -0.15 & 9.992 & $<0.01$ \\
\hline Standard deviation & 0.899 & 0.827 & & 0.907 & 0.963 & & & \\
\hline (18) I know how I am being evaluated & 3.50 & 3.66 & +0.16 & 3.72 & 3.61 & -0.11 & 3.809 & $=0.05$ \\
\hline Standard deviation & 0.959 & 0.926 & & 0.872 & 0.882 & & & \\
\hline
\end{tabular}

a n = 121 (experimental), 175 (control).

\section{Discussion}

These results provide important and exciting preliminary evidence related to our original research questions: Will the use of ePEARL benefit students by: (1) increasing their development of ICT skills; (2) enhancing motivational and cognitive benefits through a scaffolded, technology-based SRL environment; and (3) improving core foundational competencies, including literacy.

Students who used ePEARL in medium or high implementation classrooms demonstrated learning gains on a standardized literacy measure and reported positive changes in key SRL skills. Teachers in these classrooms also reported how the use of ePEARL had a positive impact on their SRL teaching strategies (Meyer, Abrami, Scherzer, \& Wade, 2009). The findings from this study offer us valuable insight into how the consistent and appropriate use of digital portfolios in general, and ePEARL in particular, impacts student metacognitive abilities, literacy achievement, as well as approaches to teaching and integrating technologies in the classroom.

Electronic portfolios are promoted as knowledge tools that are designed to facilitate the integration of technology in classrooms by being fully embedded into classroom life rather than merely added to it. While not all teachers accepted the practice of ePEARL use for reasons addressed in a separate paper (Meyer et al., 2009), we were able to achieve this result in about half the experimental venues. In these classrooms, we documented for the first time the positive impact on learning and self-regulation that a process portfolio can achieve by using a tool, the constructed response subtest of the CAT-4, that is not especially sensitive to small, subtle changes in student literacy skills.

The underlying mechanisms responsible for the change in students' literacy and self-regulation skills are not definitively known. Nevertheless, we can speculate that the purposeful acts of self-regulation - planning, doing and reflecting - as well as the engaging and authentic use of multimedia for the creation of artifacts in ePEARL both contributed to these improvements. Similarly, the increased teacher emphasis on SRL in medium-high implementation classrooms may also have played an important role in student growth. A follow-up study now underway in high implementation ePEARL classrooms may provide additional, important insights into portfolio practices and self-regulatory judgments.

\subsection{Cautions and limitations}

The strengths of this research include: the size and geographic diversity of the participants; the integration of the tool as part of classroom practice in medium and high implementation classrooms; the length of the study; and the use of a standardized achievement measure compatible with the underlying philosophy of portfolios. The weaknesses of this research relate mostly to research design. We used a strong quasi-experimental design but not a true experimental design and we needed to account statistically for pre-test differences among the groups. Although the significant ePEARL effect on writing is in the form of a small disordinal interaction, the possibility remains that some of the effect may be attributable to differential regression effects. We also suffered from experimental group attrition such that despite training, support, and follow-up, there were low implementation classrooms that were dropped from the final data set. Class sizes of the remaining experimental group teachers were smaller than the control group. Experimental teachers may have been more open to innovative teaching practices, or more enthusiastic teachers than control teachers. Additionally, the research team provided external support for experimental teachers and schools. These and other explanations are possible rival explanations to the impact of ePEARL on students' literacy and SRL skills.

We do not believe these explanations are entirely plausible rival explanations. Experimental and control teachers and their classrooms were preselected to be similar and we largely controlled for student inequivalence and other threats to internal validity using a non-equivalent pre-test-post-test control group design. Research on class size (Canadian Council on Learning, 2005; McGiverin, Gilman, \& Tillitski, 1989; Smith \& Glass, 1980) shows positive effects on learning only when class sizes are quite small. Finally, using technology for learning, especially when the technology is intended to support the process of student self-regulation, is not a straightforward teaching strategy to master and its difficulty may help to explain teacher attrition and why some effects were insignificant. As Table 1 shows, even after 6 months the teachers had not fully mastered the use of electronic portfolios in 
their classrooms and had not completely learned how to use ePEARL to encourage student self-regulation; they struggled to gain mastery. Consequently, we speculate that the external support probably did not give the experimental teachers an unfair advantage compared to control teachers.

\subsection{Conclusion: implementation issues in the use of electronic portfolios}

On the basis of studying ePEARL's use in classrooms both in this study and over several years (Abrami \& Barrett, 2005; Abrami et al., 2008; Wade et al., 2005), we have learned some valuable lessons:

1. The use of portfolios should be a school-based or board- (district-) based initiative. Use of ePEARL in one or two classrooms, once or twice a week will have a smaller impact.

2. The use of portfolios should begin early in students' educational experience and not be short-lived. The processes of self-regulation and approaches to pedagogy that portfolios support require time for younger students to learn and effort for older students to make the transition from traditional, teacher-directed methods.

3. Teachers need to develop facility with portfolio processes and they should be supported with appropriate professional development.

4. EPs provide the means to scaffold teachers and students in the portfolio process and better encourage self-regulation although these tools are not a sufficient condition for change.

5. Students and teachers must believe that the change to using a process portfolio is valued and necessary for authentic, more meaningful learning. The "will" component of SRL is as important as the "skill" component.

This last observation is perhaps the most important. This research project has operated under the assumption that learners benefit from knowledge tools for learning, and that they need to learn how to use them in order to see achievement gains. However, do learners and their teachers see the value in using these tools for learning? And do learners want to learn how to use them? These questions touch on a number of dilemmas in contemporary education - the challenges of creating and sustaining effective student-centred learning environments, the difficulties in integrating technology in classrooms, and the obstacles to switching pedagogy from emphasizing what content is to be learned to emphasizing how content is to be learned. More particularly, answering these questions may help explain the failure of other researchers to document wide-scale and faithful implementation of other electronic portfolios and the inability to document the impact of tool use on teachers and their students.

It is our hope that the findings of this research will encourage school leaders and teacher educators to recognize the value and importance of EPs to support self-regulated learning. This study indicates that students improve in their writing and certain SRL skills when an ePEARL is used regularly and appropriately throughout the school year. In order for this effective integration of ePEARL, or any other technological and pedagogical innovation to happen, school leaders, teacher educators, and pedagogical support staff need to provide consistent positive support to teachers as they learn to teach with new technologies and work within the changing realities of their school environments.

\section{Acknowledgments}

Funding for this research was made possible by grants from: the Canadian Council on Learning, the Canadian Language and Literacy Research Network, the Social Sciences and Humanities Research Council (Canada), and Fonds Québécois de la Recherche sur la Société et la Culture (Quebec). The authors express their appreciation to Vanitha Pillay for her assistance in the conduct of this research.

\section{References}

Abrami, P. C. (in press). On the nature of support in computer-supported collaborative learning using study. Computers in Human Behavior. doi:10.1016/j.chb.2009.04.007. Abrami, P. C., \& Aslan, O. (2007). The student learning strategies questionnaire. Montreal, Quebec: Centre for the Study of Learning and Performance, Concordia University Abrami, P. C., \& Barrett, H. (2005). Directions for research and development on electronic portfolios. Canadian Journal of Learning and Technology, 31(3). [<http://www.cjlt.ca/ abstracts.html>].

Abrami, P. C., Bernard, R. M., Wade, A., Schmid, R. F., Borokhovski, E., Tamim, R., et al. (2006). A review of e-learning in Canada: A rough sketch of the evidence, gaps and promising directions. Canadian Journal of Learning and Technology, 32(3), 1-70.

Abrami, P. C., Aslan, O., \& Nicolaidou, I. (2007). The teaching and learning strategies questionnaire. Montreal, Quebec: Centre for the Study of Learning and Performance, Concordia University.

Abrami, P. C., Savage, R., Wade, A., Hipps, G., \& Lopez, M. (2007). Using technology to assist children learning to read and write. In T. Willoughby \& E. Wood (Eds.), Children’s learning in a digital world. Oxford, UK: Blackwell Publishing.

Abrami, P. C., Wade, A., Aslan, O., Bures, E. M., \& Bentley, C. (2008). Encouraging self-regulated learning through electronic portfolios. Canadian Journal of Learning and Technology, 34(3). [<http://www.cjlt.ca/index.php/cjlt/issue/view/66> ].

Arter, J. A., \& Spandel, V. (1992). Using portfolios of student work in instruction \& assessment. Educational Measurement: Issues \& Practice, 11(1), 36-44.

Attwell, G. (2007). The personal learning environments - The future of eLearning? eLearning Papers, 2(1). < http://www.elearningeuropa.info/files/media/media11561.pdf > Retrieved on 13.12.09

Avramidou, L., \& Zembal-Saul, C. (2003). Exploring the influence of web-based Portfolio development on learning to teach elementary science. Journal of Technology and Teacher Education, 11(3), 415-442.

Azevedo, R. (2005). Using hypermedia as a metacognitive tool for enhancing student learning? The role of self-regulated learning. Educational Psychologist, 40(4), 199-209.

Barrett, H. C. (2007). Researching electronic portfolios and learner engagement: The REFLECT initiative. Journal of Adolescent \&Adult Literacy, 50(6), 436-449.

Barrett, H. C. (2008). The REFLECT initiative: A research project to assess the impact of electronic portfolios on student learning, motivation and engagement in secondary schools. Final report presented to national educational computing conference. $<$ http://electronicportfolios.com/portfolios.html $>$ Retrieved on 13.12 .09 [July 1].

Barrett, H. C. (2009). Online personal learning environments: Structuring electronic portfolios for lifelong and life wide learning. On the Horizon, 17(2), 142-152. <http:// docs.google.com/Doc?id=dd76m5s2_39fsmjdk $>$ Retrieved 13.12.09.

Bernard, R. M., Bethel, E., Abrami, P. C., \& Wade, A. (2007). Introducing laptops to children: An examination of ubiquitous computing in grade three reading, language, and mathematics. Canadian Journal of Learning and Technology. <http://www.cjlt.ca/index.php/cjlt/issue/view/20]V33(3) Fall / automne>.

Blackburn, J. L., \& Hakel, M. D. (2006). Enhancing self-regulation and goal orientation with eportfolios. In A. Jafari \& C. Kaufman (Eds.), Handbook of research on eportfolios (pp. 83-89). Hershey, PA: Idea Group.

Bures, E., Barclay, A., Abrami, P., \& Meyer, E. (2009). Contextualizing student assessment: How can teachers effectively assess electronic portfolios? Paper to be presented at the 2009 European Association of Research and Learning in Instruction (EARLI), Amsterdam, The Netherlands.

Campuzano, L., Dynarski, M., Agodini, R., Rall, K., \& Pendleton, A. (2009). Effectiveness of reading and mathematics software products: Findings from two student cohorts. Washington, DC: Report for US Department of Education, Institute of Education Sciences.

Canadian Achievement Tests, Fourth Edition (2008). Markham, ON: Canadian Test Centre.

Canadian Council on Learning (2005). Making sense of the class size debate. Lessons in learning. $<$ http://www.ccl-cca.ca/CCL/Reports/LessonsInLearning/LiL-14sep2005.htm> Retrieved 15.02.08 [September 14].

Canadian Council on Learning (2008). E-Learning in Canada: The promise and potential. Thematic report, Ottawa, The Council.

Carney, J. (2005). What kind of electronic portfolio research do we need? Paper presented at the society for information technology and teacher education, Phoenix, Arizona.

Cuban, L. (1993). Computers meet classroom: Classroom wins. Teachers College Record, 95(2), 185-210.

Cuban, L., Kirkpatrick, H., \& Peck, C. (2001). High access and low use of technologies in high school classrooms: Explaining an apparent paradox. American Educational Research Journal, 38(4), 813-834.

CEO Forum on Education and Technology (2001). Key building blocks for student achievement in the 21st century: Assessment, alignment, accountability, access, analysis. $<$ www.ceoforum.org/downloads/forum3.pdf $>$ Retrieved 22.07.08. 


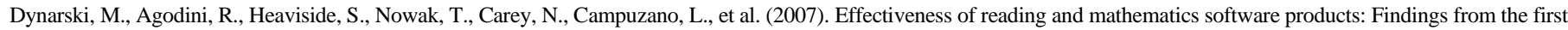
student cohort. Report for US Department of Education, Institute of Education Sciences, Washington, DC.

Hillyer, J., \& Ley, T. C. (1996). Portfolios and second graders’ self-assessments of their development as writers. Reading Improvement, 133, 148-159.

Kim, P., \& Olaciregui, C. (2008). The effects of a concept map-based information display in an electronic portfolio system on information processing and retention in a fifthgrade science class covering the Earth's atmosphere. British Journal of Educational Technology, 39(4), 700-714.

Lambert, c., DePaepe, J., Lambert, L., \& Anderson, D. (2007). ePortfolios in action. Kappa Delta Pi Record, 43(2), 76-81 [Winter 2007].

Lee, E., Chan, C., \& van Aalst, J. (2006). Students assessing their own collaborative knowledge building. Computer-Supported Collaborative Learning(1), $277-307$.

MacIsaac, D., \& Jackson, L. (1994). Assessment processes and outcomes: Portfolio construction. New Directions for Adult and Continuing Education, 62, 63-72.

McGiverin, J., Gilman, D., \& Tillitski, C. (1989). A meta analysis of the relation between class size and achievement. Elementary School Journal, 90(1), 47-56.

Meyer, E., Abrami, P., Scherzer, R., \& Wade, A. (2009). Electronic portfolios in the classroom: Factors impacting teachers' integration of new technologies and new pedagogies. Paper presented at the annual meeting of the American educational research association, San Diego, CA.

Mills-Courts, K., \& Amiran, M. R. (1991). Metacognition and the use of portfolios. In P. Belanoff \& M. Dickson (Eds.), Portfolios process and product. Portsmouth: Boynton/Cook Publishers Heinemann.

Perry, N. E. (1998). Young children’s self-regulated learning and contexts that support it. Journal of Educational Psychology, 90, 715-729.

Ravet, S. (2008). ePortfolio state of the art. < www.eipil-pan.eu/upload/documentsdownload.asp?file..pdf $>$ Retrieved on 13.12.09

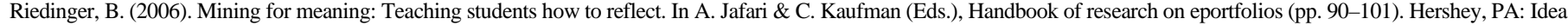
Group.

Smith, M. L., \& Glass, G. (1980). Meta-analysis of research on class size and its relationship to attitudes and instruction. American Education Research Journal, 17(4), 419-433. SPSS for Mac OS X, Rel 11.0.04 (2005). Chicago: SPSS Inc.

Ungerleider, C., \& Burns, T. (2003). A systematic review of the effectiveness and efficiency of networked ICT in education. A state of the field report to the council of ministers of education, Canada and industry Canada. <http://www.cmec.ca/stats/SystematicReview2003.en.pdf $>$ Retrieved 27.04.07.

Wade, A., Abrami, P. C., \& Sclater, J. (2005). An electronic portfolio to support learning. Canadian Journal of Learning and Technology, 31(3), 33-50. [<http://www.cjlt.ca/ index.php/cjlt/issue/view/13>].

Wall, K., Higgins, S., Miller, J., \& Packard, N. (2006). Developing digital portfolios: Investigating how digital portfolios can facilitate pupil talk about learning. Technology, Pedagogy, and Education, 15(3), 261-273.

Wang, C. (2009). Comprehensive assessment of student collaboration in electronic portfolio construction: An evaluation research. TechTrends, 53(1), 58-66.

Wozney, L., Venkatesh, V., \& Abrami, P. C. (2006). Technology implementation questionnaire. Montreal, Quebec: Centre for the Study of Learning and Performance.

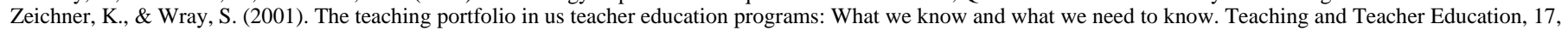
613-621.

Zellers, M., \& Mudrey, R. (2007). Electronic portfolios and metacognition: A phenomenological examination of the implementation of e-Portfolios from the Instructors' perspective. International Journal of Instructional Media, 34(4), 419-430.

Zimmerman, B. (1989). A social cognitive view of self-regulated academic learning. Journal of Educational Psychology, 81, 329-339.

Zimmerman, B. J. (2000). Attaining self-regulation: A social-cognitive perspective. In M. Boekaerts \& P. R. Pintrich (Eds.), Handbook of self-regulation (pp. 13-39). New York: Academic Press.

Zimmerman, B. J. (2008). Investigating self-regulation and motivation: Historical background, methodological developments and future prospects. American Educational Research Journal, 45(1), 166-183.

Zimmerman, B. J., \& Tsikalas, K. E. (2005). Can computer-based learning environments (CBLEs) be used as self-regulatory tools to enhance learning? Educational Psychologist, 40(4), 267-271.

Zubizarreta, J. (2004). The learning portfolio: Reflective practice for improving student learning. Bolton: Anker. 